\title{
O SETOR ELÉTRICO E A QUESTÃO AMBIENTAL: ECONOMIA DE MERCADO, ECONOMIA DE COMANDO, ECONOMIA REAL
}

\author{
Claudio Antonio Scarpinella ${ }^{1}$ \\ Sinclair Mallet Guy Guerra ${ }^{2}$ \\ Ildo Luis Sauer ${ }^{3}$
}

\section{INTRODUÇÃO}

Tradicionalmente o principal enfoque no tratamento das questões ambientais associadas à produção e transmissão de energia elétrica tem sido o econômico. Entretanto, a dimensão estratégica do papel da eletricidade na economia, as alterações das condições para uso das águas nos rios aproveitados para a construção de hidroelétricas, e a segurança do suprimento de combustíveis para as termelétricas determinam a importância também do enfoque político (entendido dentro do quadro institucional tradicional).

$\mathrm{O}$ estudo das questões políticas ambientais foi tradicionalmente subordinado ao tratamento econômico dado às alterações ambientais e a como estas alterações afetam seres humanos e comunidades. Por sua vez, a teoria econômica tem sido desenvolvida na direção de extensões que passam a compreender modos de monetarização das alterações ambientais.

O presente trabalho pretende mostrar, a partir do exemplo brasileiro, a importância da estrutura e das dinâmicas de interação social no

\footnotetext{
${ }^{1}$ Pesquisador associado do PIPGE/IEE/USP. Doutor em Energia pela mesma instituição.

${ }^{2}$ Professor associado do DE/FEM/Unicamp. Doutor em Economia da Energia pela Université Paris III.

${ }^{3}$ Professor associado do PIPGE/IEE/USP. Doutor em Eng. Nuclear pelo MIT/USA. Atualmente Diretor de Gás e Energia da Petrobras.
} 
desencadeamento e resolução das disputas geradas por crescimentos do setor elétrico que alteram o meio ambiente. Em particular, a identificação dos grupos de interessados - os stakeholders - permite melhor separar componentes mais ou menos científicos, mais ou menos ideológicos das diferentes visões e análises de custo e benefício aplicados a projetos e programas. E a entender porque os discursos dos responsáveis pelos projetos tem sido pouco adequados para um verdadeiro processo de negociação entre as partes.

$\mathrm{O}$ artigo começa por uma introdução histórica do setor elétrico brasileiro. Em seguida, delimita o paradigma tradicional de análise e a sua principal ferramenta: a análise custo-benefício. Lembra também a ofensiva neoliberal dos anos 90. A quarta parte desenvolve uma descrição dos principais conflitos políticos do setor elétrico, na perspectiva das categorias de interessados, chamadas de atores sociais. As conclusões apontam na direção dos possíveis caminhos para uma evolução das instituições e visões que permitam a construção de decisões aceitáveis para parcelas suficientemente amplas da sociedade.

\section{CONSIDERAÇÕES GERAIS: UM HISTÓRICO DO SETOR}

O setor elétrico do Brasil sofreu no passado recente um processo de reestruturação semelhante ao de vários outros países, principalmente do terceiro mundo. As bases desse processo situam-se no âmbito das políticas do assim chamado "Consenso de Washington", que, no caso, passou pela cisão das empresas em três atividades: geração, transmissão e distribuição. Deve, também, ser considerada a preparação para sua venda a grupos privados, já que o setor era quase exclusivamente estatal. Em 2002, as empresas de distribuição haviam sido vendidas na sua totalidade, assim como parte (minoritária) das de geração e de transmissão.

É importante destacar que tais medidas originaram-se integralmente no exterior, sendo adotadas pelas elites dirigentes e implantadas com apoio praticamente unânime e incondicional da imprensa e meios de comunicação nacionais. O chamado paradigma liberal, base teórica para o processo de privatização - tanto no Brasil como no resto do mundo - sempre esteve presente em debates sobre política econômica e, em particular, sobre a questão da energia elétrica. Na década de 1950, particularmente até 1957, ocorreu uma importante discussão sobre a propriedade e controle estatal da energia elétrica. Entretanto, no período imediatamente anterior ao início do processo de reestruturação, estas questões não estavam na ordem do dia. A 
iniciativa veio de fora do país, com a onda "neoliberal" impulsionada pelo Consenso de Washington. Estas mudanças tiveram o apoio explícito do governo americano:

\begin{abstract}
A Enron, com sede em Houston, está na vanguarda de um forte movimento que espera "financializar" (o termo é usado pela Enron) praticamente tudo - ou seja, comercializar quase tudo como se se tratasse de opções de ações. Esse movimento tem implicações políticas e empresariais, e a empresa não tem hesitado em usar suas conexões políticas para levar em frente a sua causa. ${ }^{4}$
\end{abstract}

Convém deter-se um pouco no significado da adoção das teses liberais na política de serviços públicos de energia elétrica. Esta tem sido alvo de controvérsias praticamente desde que a sociedade tomou conhecimento de sua importância econômica e social, no início do século XX. Ao crescer para além de uma determinada escala, as atividades das empresas locais de energia elétrica, formadas em torno de pequenas centrais térmicas e de aproveitamentos hidroelétricos locais, foram sendo assumidas por empresas americanas e canadenses, chamadas na época de trusts, e atualmente de holdings, que passaram a ser os responsáveis pelo fornecimento dos serviços cada vez mais importantes para a economia e para os cidadãos.

Conflitos em torno da fixação das tarifas e das questões relacionadas com o uso da terra e de suas rendas associadas não tardaram a surgir, ${ }^{5}$ ao longo da primeira metade do século vinte e nos anos cinqüenta.

Segundo o ministro da Agricultura da época, Juarez Távora, "a Light encabeçou resistências ao cumprimento desses preceitos legais" do novo Código (de Águas). Este foi nas décadas seguintes responsabilizado pela escassez de energia elétrica, em particular nos estados em que esta era explorada, uns pela Light, outros pela Bond and Share. ${ }^{6}$

Tais conflitos acabaram levando a um crescimento da intervenção governamental no setor, por meio de legislação específica. Nesse aspecto destacam-se o Código de Águas, inspirado na legislação americana e aprovado em 1934, após mais de vinte anos de deliberações legislativas, e o início da construção de projetos federais de usinas hidrelétricas com fortes

${ }^{4}$ KRUGMAN, P. O poder da Enron. O Estado de São Paulo, 18 ago. 2001, traduzido do New York Times.

${ }^{5}$ VASCONCELlOS, M. C., p. 120. BRANCO, C. Energia elétrica e o capital estrangeiro no Brasil. São Paulo: Alfa-Omega, 1975. p. XV, 70.

${ }^{6}$ BRANCO, op cit., p. XV. 
motivações de planejamento regional. Tais projetos incluem a constituição da Companhia Hidrelétrica do São Francisco - Chesf e da Companhia Hidrelétrica de Furnas, entre as décadas de quarenta e cinqüenta, seguidas da entrada de empresas estaduais, do sudeste e do sul do país.

A partir da criação da Eletrobras - por meio de projeto de lei apresentado em 1954 por Getúlio Vargas e sancionado apenas em 1961, por Juscelino Kubitschek - e de iniciativas dos governos estaduais durante o período de governo militar, a geração e a quase totalidade da distribuição de energia elétrica no Brasil foram assumidas por empresas públicas estatais. Essas empresas expandiram a oferta de energia elétrica em grau sem precedentes, eliminando os racionamentos que vinham ocorrendo nas áreas já cobertas pelas redes de distribuição, comuns nas décadas precedentes. Em 1965, a capacidade instalada de empresas públicas representava 54,5\%, contra $33,5 \%$ de concessionárias privadas e $12 \%$ de autoprodutores. Por volta de 1979, cessou a presença estrangeira no setor, e as concessões privadas de distribuição remanescentes pertenciam a grupos privados brasileiros que cobriam algumas regiões do interior do país. A maior parte do setor havia sido estatizada. ${ }^{7}$

Nesse período, os vícios de uma estrutura burocratizada e sujeita a interferências de naturezas diversas por parte de políticos do executivo e do legislativo, levaram a proposições de mudanças no modo de atuar das empresas do setor. Essas mudanças deveriam, a par de garantir uma remuneração adequada aos investimentos, aumentar a eficiência e produtividade, assim como

conceder estímulos à formação de pessoal técnico e à padronização de instalações dos equipamentos dos serviços de eletricidade.

Nesse, parecia necessário ao Governo "privatizar" o setor de energia elétrica, entendendo-se "privatizar de modo especial: embora um serviço de utilidade pública, o setor deveria ser gerido pelos padrões de empresa privada, não obstante a tarifa

${ }^{7}$ LIMA, J. L. Políticas de governo e desenvolvimento do setor de energia elétrica: do código de águas à crise dos anos 80. Rio de Janeiro: Memória da Eletricidade, 1995. p. 99-112. Na época, houve uma antecipação da reversão da concessão da Light em dois anos, pelo que o Governo Brasileiro pagou uma quantia considerada excessiva por muitos. Considerando os conflitos de até pouco mais de quinze anos antes, houve pequena repercussão. A única oposição à operação veio dos setores de esquerda, que consideraram o negócio prejudicial ao país, já que dentro de dois anos a reversão seria de graça. 
continuasse a ser fixada pelo Governo (mas a níveis satisfatórios para as empresas)". ${ }^{8}$

A crise cambial e financeira que se iniciou em 1980 prejudicou a saúde financeira das empresas estatais de energia elétrica. Dando origem, assim, a mais de uma tentativa de reestruturação financeira e sendo uma das justificativas para o desencadeamento do processo de privatização.

A crise financeira internacional de 1980 revelou o grave quadro de estrangulamento econômico-financeiro do setor público. De acordo com Belluzzo, o "padrão de financiamento da economia e do setor público, fortemente apoiado durante os anos 70 no endividamento externo, entrou em colapso. ${ }^{9}$

Aspecto importante da história do setor elétrico brasileiro e que pode lançar luz sobre o caráter da evolução histórica da economia do país foi o constituído pelos acirrados debates que se deram no âmbito das políticas governamentais para o setor, particularmente entre 1930 e $1964 .{ }^{10}$ Os atores sociais desses debates foram juristas, técnicos brasileiros, dirigentes das empresas estrangeiras e titulares dos ramos do Executivo que lidavam com estas questões. Quase desde o início estabeleceram-se polarizações entre posições nacionalistas, que advogavam maior controle (não necessariamente estatização) dos serviços públicos de energia, de um lado, e liberais, que defendiam poder e liberdade de ação para as concessionárias.

A história do setor ao longo desses anos é definida pela sua estrutura microeconômica - caráter de serviço público e de monopólio natural - e pelos condicionantes econômicos e históricos dentro dos quais ele cresceu. No entanto, seria incompreensível sem o conhecimento das motivações e modos de agir dos setores sociais participantes do planejamento e operação do sistema, dos consumidores e dos membros dos três poderes da República.

As definições estruturais determinaram os contornos de um paradigma para o setor, por muito tempo aceito de forma quase unânime.

${ }^{8}$ CALABI, A. S. (Org.). A energia e a economia brasileira. São Paulo: Fipe/ Pioneira, 1983, p. 109.

${ }^{9}$ LIMA, op. cit., p. 120.

${ }^{10}$ BARBOSA LIMA SOBRINHO. In: BRANCO, op.cit., p. XIV-XXXI. 


\section{O PARADIGMA DO SETOR ELÉTRICO}

Em seus primórdios, a energia elétrica passou por um curto período em que teve um caráter de serviço mais ou menos restrito. Logo no início do século 20, entretanto, já adquiria as características de serviço público. Este distingue-se de uma mercadoria por características que acabam por exigir uma intervenção extra-mercado e que compreendem, na visão mais geral, os quatro pontos seguintes:

- Estar disponível a todos os indivíduos e famílias da sociedade, do ponto de vista geográfico e de poder aquisitivo;

- Ter tarifa razoável, o que geralmente se entende por acessível a todos, e suficiente para cobrir os custos totais do serviço;

- Ser fornecida com qualidade e cortesia;

- Estar enquadrada dentro de uma estratégia sustentável quanto ao meio ambiente. ${ }^{11}$

O processo de expansão do serviço teve uma evolução histórica própria, que se deu por meio de várias categorias de conflitos de caráter local, regional e internacional, e ocorreu em uma sociedade composta por interesses individuais e coletivos bastante fluidos e diversos. Tendo partido de origens locais e limitadas, os serviços de eletricidade cresceram e desenvolveram-se até que o conjunto das características de serviços públicos se tornasse predominante.

Evidentemente o serviço de energia elétrica jamais satisfez integralmente (ou ao menos de modo satisfatório) as citadas quatro características dos serviços públicos, do ponto de vista dos vários agentes sociais. As extremas desigualdades regionais e sociais e uma renda per capita que permanece medíocre explicam boa parte dessa limitação. O caráter de monopólio natural, ao concentrar os poderes econômico e de informação na empresa concessionária também contribui para isso. Entretanto, o cumprimento das quatro características pode ser considerado um objetivo básico permanente a ser perseguido mediante o trabalho de atores sociais dentro de estratégias definidas no âmbito do Estado.

A primeira característica do serviço público de eletricidade impõe, dentro de um quadro de atendimento insuficiente e em crescimento, que sejam expandidas as redes de distribuição, construídas novas centrais elétricas e linhas de transmissão, com alterações sobre o meio ambiente e sobre a situação física e afetiva das pessoas e comunidades. Dentro deste quadro, o

${ }^{11}$ BRANCO, op.cit., p. 63; LIMA, op.cit., p. 28-29. 
instrumento básico utilizado pelos planejadores governamentais para avaliar e selecionar alternativas para essas expansões tem sido a análise custobenefício.

\section{ANÁliSE CUSTO-BENEFÍ́CIO}

O instrumento tradicional de análise para a tomada de decisões sobre serviços públicos tem sido a Análise Custo-Benefício, pois desde que surgiu no século XIX, tendo sido utilizada extensamente durante o século $\mathrm{XX}$, sob inúmeras controvérsias quanto a suas metodologias e validade.

A lógica da Análise Custo-Benefício é simples. Enumeram-se fatores de custos e de perdas, de um lado, e receitas e benefícios de outro. Lógica semelhante é utilizada por indivíduos e instituições tanto em suas decisões de consumo ou de investimento quanto na resolução de conflitos. As dificuldades surgem na medida em que constata-se que em sistemas reais os lados positivos (ganhos) e negativos (perdas) não se aplicam de modo uniforme a todos os afetados. Procura-se, então, deduzir valores que possam - por representar um ser mais abrangente, que é o interesse público,sobrepujar os conflitos entre indivíduos e seus agrupamentos, que são os custos e os benefícios sociais.

Desde os anos oitenta, a visão neoliberal busca enfatizar os pressupostos da economia de mercado livre, inclusive estendendo a condição de mercadorias (commodities) aos serviços públicos. Essa visão veio se opor à aplicação da contabilidade social da Análise Custo-Benefício, substituindo-a por uma contabilidade privada dos atores econômicos.

\section{ENFOQUE NEOLIBERAL}

A definição básica do paradigma liberal está ligada ao indivíduo econômico. Como agricultor, industrial, comerciante ou trabalhador urbano, e ainda como consumidor, aquele procura maximizar a sua utilidade e, se todos puderem fazê-lo com liberdade e independência uns dos outros, a sociedade atingirá a prosperidade possível, ou eficiente. As condições estruturais são consideradas de importância secundária, assim como as atitudes de (e contradições entre) diferentes grupos sociais e econômicos.

Esse paradigma tem sido usado com pragmatismo pelas elites desde o início do desenvolvimento do capitalismo, moderado por interven- 
ções dos governos, na ordenação das atividades econômicas, e como grandes consumidores ou como poderes arrecadadores. Periodicamente, grupos econômicos, políticos e acadêmicos, movidos por diversos propósitos, têm conseguido impor ondas de liberalização, de durações variadas, mas limitadas, sobre sociedades mediadas por estruturas institucionais herdadas. Com esses surtos, em que pactos tácitos ou reais são rompidos em favor desses grupos, vem a proposição de modelos econômicos em que indivíduos produziriam o melhor dos mundos ao transacionar, tendo em vista exclusivamente sua utilidade, produtos e serviços, universalmente transformados em mercadorias. Uma publicação de 1940 ilustra esse debate:

\begin{abstract}
A competição", dizia Anhaia Mello, "é fenômeno biológico e econômico; fenômeno universal no mundo das coisas vivas. Estabelece ela, automaticamente, nos negócios, a qualidade e o preço dos serviços. Mas o característico econômico essencial dos serviços de utilidade pública é justamente o de se organizarem melhor como monopólios. ${ }^{12}$
\end{abstract}

Se a presunção de universalidade do homo economicus embutida no paradigma liberal for relaxada, o que certamente não contraria o senso comum aplicado a uma sociedade do mundo real, pode-se propor que a análise passe a ser baseada em diferentes sujeitos, detentores de formas de poder, bagagens culturais, e de propósitos imediatos bastante diversos, chamados de atores sociais.

\title{
ATORES SOCIAIS
}

Consideram-se aqui como atores sociais pessoas e grupos que têm interesses nas questões sociais e ambientais, cuja natureza transcende os mecanismos típicos de mercado, e que, eventualmente, assumem um papel consciente e ativo na defesa e perseguição desses interesses. Há dois enfoques na conceituação do ator social. O primeiro, proveniente do paradigma neoclássico, postula um ente único que representa a todos: o indivíduo econômico, ser cuja racionalidade consiste no propósito de maximizar o seu benefício individual. O outro, parte do exame histórico das ações de pessoas e grupos, com um grau menor de abstração, procurando

${ }^{12}$ BRANCO, op. cit., p. 62. 
delinear um conceito de ator multidimensional. O processo de abstração, nesta forma de análise, consiste em enquadrar indivíduos e grupos em categorias cujos interesses são considerados distintos e muitas vezes conflitantes com os interesses de outras categorias. Uma enumeração dos atores sociais relacionados com o setor elétrico, imediatamente antes e atualmente dentro do processo de reestruturação do setor é feita a seguir. ${ }^{13}$

No grupo inicial, em primeiro lugar, figuram os agentes que fornecem ou compram do setor de energia elétrica, com poder concentrado de barganha. Entre eles estão as empresas que consomem energia elétrica e água, empresas de engenharia e consultorias, empreiteiras, fabricantes de equipamentos para o setor - nacionais e estrangeiros -, fornecedores de novas tecnologias e novos equipamentos e fabricantes de equipamentos consumidores de eletricidade. Em segundo lugar, estão as distribuidoras, a maioria absoluta das quais estatais, de energia elétrica e de água. O setor financeiro lida nessa fase basicamente com o governo, representado pelo Dnaee e pela Eletrobras, e inclui bancos, as instituições financeiras internacionais (FMI, Banco Mundial, BID), e, como atores menores, investidores internacionais e empresas estrangeiras de eletricidade.

Em terceiro lugar, ainda entre os atores sociais diretamente relacionados com o setor, mas com menor grau de organização e poder de barganha, situam-se os consumidores não organizados, basicamente os residenciais e as pequenas empresas, e os afetados pelas obras do setor (principalmente usinas hidrelétricas), os consumidores residenciais de água, e as organizações que tratam de representar seus interesses, com maior ou menor êxito: de defesa dos consumidores, de atingidos por barragens, organizações locais. Finalmente, um quarto grupo, dos trabalhadores de energia elétrica, organizados em sindicatos com poder de barganha relativamente alto antes do processo de reestruturação.

Um quinto grupo compreende os atores sociais de presença mais geral na sociedade, que dedicam parte de sua atuação ao setor: imprensa, publicistas de questões energéticas e ambientais, setor acadêmico e comunidade de pesquisas, associações profissionais, federações regionais e nacionais de indústrias, partidos políticos, movimentos populares e organizações não governamentais, centrais sindicais, organizações de consumidores. Finalmente, os ramos do Estado: executivo, organismos reguladores e poderes legislativo e judiciário.

13 SCARPINELla, C. A. Porto Primavera: o paradigma de análise e os processos de decisão e implantação. São Paulo, 1999. Tese (Doutorado) - Universidade de São Paulo. cap. 3 
Nesta breve descrição dos papéis dos diferentes atores sociais é útil caracterizar as dinâmicas econômicas não passíveis de redução ao paradigma liberal. Eles encontram-se agrupados em diferentes categorias: empresas que lidam com o setor elétrico, com algum poder econômico nas relações com as concessionárias; estas mesmas e instituições não estatais com poder significativo (direto ou indireto) sobre elas; indivíduos ou grupos geralmente com limitado poder de barganha em relação às concessionárias; organizações influentes sobre o conjunto da sociedade; e instrumentos do Estado. Cada uma das categorias incluídas, por sua vez, pode ser decomposta em várias subcategorias mais uniformes. Esta condição pode ser importante no caso dos atores mais dinâmicos: novos operadores dos serviços de energia elétrica, organizações não governamentais.

O quadro inclui atores sociais que de alguma maneira foram "derrotados" pelo processo de reestruturação do setor, como as concessionárias estatais e seus trabalhadores organizados, apontados pelos defensores do processo como os beneficiários privilegiados da condição estatal dessas empresas no período anterior. ${ }^{14}$

Os atores sociais aqui relacionados tenderam, ao longo da história do setor, a colocar-se em um de dois grandes grupos oponentes, que podem ser chamados provisoriamente de nacionalistas e liberais. Seu embate sempre influenciou o modo de funcionamento dos órgãos do Estado, mas, até o atual processo de reestruturação por privatização do setor elétrico, as mudanças estruturais eram comandadas basicamente pela dinâmica da demanda, crescendo quase sempre de forma acelerada e das condições do setor para fazer face a essa demanda. Uma outra vertente de ação política, que muito influiu na evolução estrutural do setor foi a regional, que opôs Estados como São Paulo e Minas Gerais aos do Nordeste, de um lado, e do Sul do país, que durante o primeiro período Vargas abriu caminho para a centralização de grande parte das decisões no Governo Federal e para dar a partida a iniciativas visando ao desenvolvimento regional.

${ }^{14}$ Falando sobre a importância do desenvolvimento das pesquisas por meio das associações que vêm sendo feitas na área de petróleo, tornando possível que empresas brasileiras entrem na área de exploração do produto, o presidente Fernando Henrique Cardoso afirmou (...)que a expansão da indústria petrolífera no Brasil está criando um novo momento do nacionalismo. "Não o nacionalismo de um estado parasitário, onde as burocracias sugam, através do Tesouro, o dinheiro do povo, mas um nacionalismo voltado para a educação, saúde, meio ambiente e bem-estar". Fonte: Correio da Bahia, Salvador, 15 set. 2000 . 
Uma terceira importante vertente de ação confronta os atores sociais que "seguem as regras", de caráter basicamente ético, do serviço público e os que, embora oficialmente enquadrados no sistema, só as praticam em parte. Assim, o planejamento do crescimento do setor elétrico normalmente pressupõe os cinco princípios que devem nortear os serviços: "generalidade, permanência, eficiência, modicidade e cortesia, cabendo ao concedente o poder-dever de fiscalizar e zelar pelo atendimento dos mesmos". ${ }^{15}$ Eventualmente, formaram-se alianças entre ocupantes de cargos do poder concedente e empresas privadas do setor elétrico que favoreceram que esses princípios fossem escamoteados. Mais tarde formaram-se alianças entre as empresas públicas e fornecedores, principalmente as grandes empreiteiras de obras, visando primordialmente o lucro desses agentes privados, em oposição aos mencionados cinco princípios. Não seria razoável ignorar a importância desses "desvios" das rendas elétricas na história do setor e na gestação de suas crises, mesmo porque não se fez ainda uma avaliação a respeito de se a privatização eliminou as ações deletérias desses atores sociais, ou apenas mudou as formas de apropriação de rendas públicas e seus agentes.

O poder de intervenção dos grupos sempre teve uma forte relação com o seu poder econômico. Com a implantação de diversas propostas de legislação e de regime tarifário, reconhecido desde o início o caráter de monopólio natural do setor, a dinâmica da oferta de energia elétrica passou a ser regida por negociações de crescente complexidade.

No início da história do setor elétrico, o consumo de eletricidade foi dominado pela iluminação pública e privada. Nos grandes centros, houve, por um determinado período, competição entre gás de coque e eletricidade. Passada essa fase, ampliou-se o leque dos consumidores de energia elétrica, com destaque para o setor secundário, incluindo, mais tarde, comércio e serviços. A base de consumo residencial ampliava-se, acabando por sugerir o estabelecimento do objetivo de universalização de um serviço que adquiria as características de público.

Nesse ponto, as empresas estrangeiras passaram a dominar os serviços de energia elétrica, concentrando-se nos mercados com maior concentração de consumidores e, portanto, maior lucratividade. Em 1927, a Light, canadense e a Amforp, americana, eram responsáveis por um virtual monopólio da distribuição de energia elétrica no País. ${ }^{16}$

${ }^{15}$ SANTOS, MERCEDES e SAUER, p. 140.

${ }^{16}$ LIMA, op. cit., p. 16 
As primeiras definições do papel do Estado relativas ao uso dos cursos d'água, em um momento inicial apenas do Executivo, mas, logo também do Legislativo, ${ }^{17}$ foram desencadeadas inicialmente por iniciativa das empresas estrangeiras, que solicitaram a mediação na competição na forma de concessão dos serviços em regime de monopólio.

Desde a constituição das primeiras empresas estrangeiras de energia elétrica no Brasil, o poder político esteve profundamente envolvido nas tarefas de regulamentação, e de assegurar condições e meios de atuação para as mesmas, realidade que continuou até hoje. Muitos especialistas defendem que energia elétrica nada é mais do que uma mercadoria a ser tratada dentro do paradigma liberal de ampla e livre concorrência.

A formulação política advém do caráter de serviço público, conceito desenvolvido nas democracias de caráter político liberal. Advém também do projeto de desenvolvimento econômico, em debate no Brasil desde que foi possível compará-lo com outros mais ricos e menos dependentes. Este debate, embora altamente concentrado nas elites econômicas e culturais, começou a abranger outros estratos da sociedade, a partir do crescimento do proletariado urbano e de suas mobilizações por partidos de esquerda - comunista e socialista, e de setores da classe média, como os tenentistas, ${ }^{18}$ que chegaram ao poder com a Revolução de $1930 .{ }^{19}$

As questões relativas à geração de energia elétrica, sempre com predomínio da de origem hídrica, começaram a ser objeto de debate público já no início do século. Em 1904, após a publicação de seu livro Rios públicos e particulares, o jurista Alfredo Valadão, foi convidado pelo então ministro da Agricultura a redigir o primeiro Projeto do Código das Águas. Na época, ainda vigiam sobre os rios as Ordenações do Reino, uma Resolução de 1775, Alvará de 1804, e leis e decretos insuficientes, promulgados entre 1903 e 1905.

Esse primeiro projeto do Código de Águas, enviado à Câmara dos Deputados em 1907, não chegou a ser votado. A revolução de $1930 \mathrm{fez}$ reviver o assunto e, em 1931, foi encomendado novo projeto ao mesmo

${ }^{17}$ Esta atuação começou com a proposição de um Código de Águas em 1904.

${ }^{18}$ Chamam-se tenentistas os líderes de um movimento militar que se iniciou em 1922, com uma revolta no Rio de Janeiro, liderada por tenentes do Exército Brasileiro. Embora a revolta inicial tenha sido reprimida, seus componentes continuaram no Exército, e muitos tiveram importantes papéis na história do Brasil até a década de sessenta.

${ }^{19}$ A Revolução de 1930 fez um grande rearranjo entre as elites governantes, e, a fim de estabelecer uma ditadura que durou quinze anos, introduziu várias reformas de caráter modernizante na economia brasileira. 
Alfredo Valadão. Estudado por juristas, foi sancionado pelo chefe do governo Getúlio Vargas no Projeto 24.643, de 19 de Julho de 1934.

Segundo Branco ${ }^{20}$, o Código das Águas, (que "nunca foi levado à prática")

foi elaborado com base no trabalho de juristas americanos como Bauer e Nash. (...) e partia de uma série de princípios básicos: Quedas d'água e outras fontes de energia hidráulica são declarados bens distintos e não integrantes das terras (art.145);

As quedas d'água e outras fontes de energia hidráulica são incorporadas ao patrimônio da Nação, como propriedades inalienáveis e imprescritíveis (art. 147);

O aproveitamento industrial das quedas d'água e outras fontes de energia hidráulica será feito por concessão do Governo (art. 139);

As empresas serão fiscalizadas pelo Governo inclusive em sua contabilidade (art. 178);

As tarifas serão estabelecidas na base de serviços prestados pelo preço de custo (art. 180);

O capital das empresas será avaliado na base do custo histórico (art. 180);

As concessões só serão conferidas a brasileiros ou a empresas organizadas no Brasil (art. 195);

A maioria de diretores das empresas será constituída de brasileiros residentes no Brasil ou deverão as administrações destas empresas delegar poderes de gerência exclusivamente a brasileiros (art. $195-\S 10$.);

Deverão estas empresas manter nos seus serviços no mínimo dois terços de engenheiros e três quartos de operários brasileiros (art. $195-\S 20$ ).

Essas condições, que viriam a gerar um persistente contencioso entre autoridades e empresas de energia elétrica, baseavam-se em doutrinas e práticas em vigência nos países de onde vieram essas empresas, e onde surgiram naturalmente as primeiras questões jurídicas e administrativas nos novos setores de serviços públicos de energia.

Segundo o ministro da Agricultura da época, o futuro Marechal Juarez Távora, "a Light encabeçou resistências ao cumprimento desses preceitos legais" do novo Código. Este foi, nas décadas seguintes, responsabilizado pela escassez de energia elétrica, em particular nos Estados em que

${ }^{20}$ BRANCO, op.cit., p. 70. 
esta era explorada por holdings estrangeiras, parte deles pela Light, outra pela Bond and Share.

Esta polarização não se limitou às empresas de eletricidade e o governo Vargas, que já propiciara o surgimento de uma burocracia aliada, atuando principalmente a partir da criação do Conselho Nacional de Águas e Energia Elétrica-CNAEE, pelo Decreto-Lei 1.285, de 18 de maio de 1939, previsto, de certa forma, no Código de Águas. Na realidade, inseriu-se em um debate gerado pela comparação entre países como o Brasil e as potências da época.

A questão da energia elétrica expandiu-se para um debate público sobre as funções do Estado e da empresa estrangeira e seu papel no que veio a chamar-se mais tarde, depois da Segunda Guerra Mundial, de desenvolvimento econômico. Apesar de se dar no contexto de questões políticas do setor elétrico brasileiro, este debate na realidade teve como referência o que ocorria nos países mais ricos da América do Norte e da Europa. Lá, depois da Guerra, vários países mantiveram ou transferiram para a administração direta do Estado a produção e distribuição da energia elétrica.

Assim, a história dos anos trinta, quarenta e cinqüenta foi uma história de conflitos entre o poder concedente e as concessionárias, em torno da oferta insuficiente e do nível das tarifas. Ao fim da Segunda Guerra Mundial, e principalmente a partir do segundo período Vargas, em 1950, teve início um novo ciclo de expansão da economia baseada em uma atuação muito mais forte do Estado no planejamento e na expansão da infra-estrutura econômica.

Em junho (de 1962), o Banco Mundial, em conjunto com as autoridades brasileiras, selecionou duas firmas canadenses de consultoria - Montreal Engineering e Crippen Engineering - e uma americana - Gibbs and Hill Inc. - que formaram o Consórcio Canambra, assim designado em razão dos agentes envolvidos: Canadá, Estados Unidos da América e Brasil. O consórcio teve como objetivo iniciar amplo estudo dos potenciais hidrelétricos e do mercado de energia elétrica na região Sudeste e executou o trabalho considerado (na época) como um dos mais expressivos sobre a questão do planejamento elétrico integrado, em estreita colaboração com técnicos brasileiros das empresas de energia elétrica. A experiência adquirida por esses técnicos foi decisiva no planejamento setorial nos anos que se seguiram. ${ }^{21}$

${ }^{21}$ LIMA, op. cit., p. 105. 
Pode-se dizer que essa experiência deu aos técnicos do setor condições para assumirem uma ampla faixa de responsabilidades no setor, progressivamente estatizado ao longo das décadas de sessenta a oitenta. Esses técnicos dividiram responsabilidades com o poder político, representado principalmente pelo Executivo e, em menor escala, com os Legislativos federal e estaduais.

Os atores sociais listados ${ }^{22}$ contêm as categorias mais citadas nas publicações - artigos, livros e notícias - que tratam dos problemas de política energética.

O debate brasileiro baseou-se mais na apreciação política dos exemplos disponíveis na época, mediante uma visão antropológica sempre pessimista acerca da viabilidade de soluções autóctones satisfatórias do que em análises custo-benefício das diferentes opções. A configuração atual de atores sociais presentes no setor elétrico no período imediatamente anterior ao processo de privatização pode ser enquadrada em quatro grandes grupos: Produção e Distribuição, Consumo, Regulação e Intermediação, e Instituições de Produção de Conhecimento. ${ }^{23}$

Os poderes relativos dessas categorias têm sofrido grandes mudanças ao longo da história do setor, que aceleraram com a reestruturação ocorrida nos anos noventa e continuaram após a crise de abastecimento de energia elétrica de 2001.

O primeiro grupo, de produção e distribuição: geradoras privadas, geradoras estatais, sistema de transmissão parcialmente privatizado, sob controle do Operador Nacional do Sistema, curioso exemplo de órgão público com gestão privada, as distribuidoras privadas, distribuidoras estatais remanescentes, investidores, empresas de águas e saneamento (em parte privadas), grandes e pequenos fornecedores para o setor, formalmente sem vínculos com o Estado ou com as empresas do setor.

O grupo do consumo compreende os consumidores residenciais, os consumidores empresariais pequenos e médios, grandes consumidores industriais e comerciais. Um grupo de Regulação e Intermediação compreende a Aneel - Agência Nacional de Energia Elétrica-, agências estaduais, regionais e municipais, o poder executivo, na formulação de políticas, o legislativo e o judiciário, muito ativos nos últimos anos na apreciação e aprovação de novas leis e na sua aplicação, e partidos políticos, que têm

${ }^{22}$ Lista elaborada pelo autor, sem a intenção de ser uma classificação completa e abrangente de componentes.

${ }^{23}$ SCARPINELLA, op.cit., cap. 3. 
procurado intervir na questão em função de sua visões estratégicas e de outros interesses.

Finalmente, um grupo que pode ser chamado de Instituições de Acumulação de Forças, nas quais são engendradas as propostas e os meios de conseguir sua aceitação pelos outros atores: organismos financeiros internacionais, governos dos Estados Unidos da América e de outras economias dominantes, sindicatos de trabalhadores do setor, sindicatos de setores próximos e centrais sindicais hoje com menos força, movimentos populares e organizações não governamentais, em forte crescimento, organizações de consumidores, os partidos políticos, imprensa escrita, mídia (incluindo rádio, televisão e internet), publicações especializadas, e universidades e institutos de pesquisas, todos, com exceção dos dois últimos, sofrendo profundas mudanças nos últimos anos.

Nestas mudanças tem faltado, mesmo em períodos de maior mobilização política da sociedade brasileira, como o que se deu entre o fim da Segunda Guerra Mundial e o início do regime militar em 1964, um debate mais amplo sobre a estrutura do setor elétrico e sua inserção na geografia e na economia. Falta, assim, um lugar público que inclua todos os interessados para as negociações envolvendo as grandes questões do setor.

\section{RESUMO}

O processo de decisões quanto às alterações ambientais causadas pela construção e operação do sistema de produção e transmissão de energia elétrica tem sido tradicionalmente instruído pela sua análise econômica do ponto de vista empresarial. Uma análise custo-benefício seria suficiente, dentro deste enfoque. Entretanto, a natureza dessas alterações transcende o cálculo econômico feito sob os parâmetros da teoria econômica neoclássica. Nada mais distante de uma coletividade de indivíduos que maximizam suas utilidades, do que os indivíduos que têm poder de influir sobre as decisões mais importantes do setor. O exame histórico da evolução do setor elétrico no Brasil mostra um cenário em que diferentes grupos de atores sociais ou stakeholders, vêm aplicando diferentes paradigmas de análise nas decisões quanto ao uso dos recursos hídricos, alterações nos cursos d'água e na atmosfera. O estudo da dinâmica de evolução dos vários atores sociais, e das relações e embates entre eles são fundamentais para a compreensão do processo histórico. Permite também uma adequada separação e atribuição dos interesses e objetivos aos 
diversos grupos, pressuposto para qualquer tentativa de síntese em nome de um interesse mais amplo.

Palavras-chave: setor elétrico, meio ambiente, atores sociais.

\begin{abstract}
The decision making process for the environmental alterations caused by the construction and operation of power plants and transmission system has been instructed traditionally by economical analysis of the business point of view. A cost-benefit analysis would be sufficient, inside of this focus. However, the nature of those alterations transcends economic calculations done under the parameters of the neoclassical economical theory. The individuals that have power of influence over the most important decisions of the power industry couldn't be more distant of a collectivity of individuals that maximize their utilities. The historical examination of the evolution of the power industry in Brazil shows a scenario in that different groups of stakeholders apply different analysis paradigms in the decisions as for the use of hydro resources, alterations in the water bodies and in the atmosphere. The study of the dynamics of the several social actors' evolution, and of the relationships and collisions among them are fundamental for the understanding of the historical process. It also allows an appropriate separation and attribution of the interests and objectives to the several groups, presupposition for any synthesis attempt on behalf of a wider interest.

Key-words: power industry, environment, stakeholders.
\end{abstract}

\title{
REFERÊNCIAS
}

BRANCO, Catulo. Energia elétrica e o capital estrangeiro no Brasil. São Paulo: AlfaOmega, 1975.

CALABI, Andrea S. (Org.). A energia e a economia brasileira. São Paulo: Fipe/Pioneira, 1983.

KRUGMAN, Paul. O poder da Enron. O Estado de São Paulo, 18 ago. 2001. Tradução do New York Times.

LIMA, José Luiz. Politicas de governo e desenvolvimento do setor de energia elétrica: do Código de Águas à crise dos anos 80. Rio de Janeiro: Memória da Eletricidade, 1995. MEMÓRIA DA ELETRICIDADE. Caminhos da modernização - cronologia do setor de energia elétrico brasileiro. Rio de Janeiro, 1999. 
SCARPINELLA, C. A.; GUERRA, S. M. G.; SAUER, I. L. O setor elétrico e...

SANTOS, Rosana R.; MERCEDES, Sonia S.; SAUER, Ildo L. A reestruturação do setor elétrico brasileiro e a universalização de acesso ao serviço de energia elétrica. Revista Brasileira de Energia, v. 7, n. 2, 2º sem. 1999.

SCARPINELLA, Claudio A. Porto Primavera: o paradigma de análise e os processos de decisão e implantação. São Paulo, 1999. Tese (Doutorado) - Universidade de São Paulo. VASCONCELlOS, M. C. Usos múltiplos da água em São Paulo. História e Energia, São Paulo: Eletropaulo, 1995. 